\title{
The Melbourne Declaration on Diabetes
}

\author{
ADRIAN M SANDERS
}

\begin{abstract}
Advances in science and technology, mainly during the 20th century, have facilitated extended survival amongst those for whom such ailments would previously have been a death sentence. Despite its increasing prevalence amongst people of all ages and its far-reaching ramifications, diabetes is in danger of being diluted in an ever increasing murky pool of long term conditions. The Melbourne Declaration on Diabetes, described herein by the first President of the Parliamentary Diabetes Global Network, aims to raise the profile of the condition and spur action to address the diabetes pandemic.
\end{abstract}

Key words: diabetes, Melbourne Declaration, pandemic, political

\section{Introduction}

There is a great deal of cross-national communication among medical professionals, pharmaceutical companies, health ministers and patient groups but until now nothing for parliamentarians who can set the agenda, influence budgets and vote for policies.

For example, EURADIA facilitates cross fertilisation between healthcare professionals, researchers and industry. The St Vincent Declaration was an early European effort to bring together government health officials, patient organisations and diabetes experts to agree general goals and standards of diabetes care and ways to improve the lives of people with diabetes - setting 5 year targets, some being more realisable than others..$^{1-3}$ Indeed in the first issue of this journal there is a copy of a letter from the Prime Minister of the day endorsing the 10 years of activity prompted by the 1989 Declaration. ${ }^{4}$ More recently the UN resolution (61/225) designating World Diabetes Day (14th November) as a UN day has furthered international recognition of the increasing prevalence and impact of diabetes. ${ }^{3}$

Member of Parliament, House of Commons, London, UK

Address for correspondence: Mr Adrian M Sanders MP House of Commons, London, SW1A OAA, UK

Tel: +44 (0)20 72192390

E-mail: sandersa@parliament.uk

Br J Diabetes Vasc Dis 2014;14:35-37

http://dx.doi.org/10.15277/bjdvd.2014.007

\author{
Abbreviations and acronyms \\ ExPAND European Policy Action Network for Diabetes \\ MP Member of Parliament \\ PDGN Parliamentary Diabetes Global Network \\ UN United Nations
}

\section{Melbourne}

On 2nd December 2013 invited parliamentarians representing 50 countries attended the first PDGN meeting in Melbourne, Australia. At this meeting in the Victoria State Parliament building, MPs from across the globe reported on the state of diabetes care in their countries, discussed how to raise the profile of the condition and agreed and signed a declaration calling for urgent action to address the diabetes pandemic. ${ }^{5}$ It committed the signatories to work across parliaments to help prevent diabetes, ensure early diagnosis and improve the treatment of people with the condition (Box 1).

The PDGN, which is the first global network of parliamentarians for a specific medical condition, elected two Vice-Presidents, Dr Rachael Nyamai MP (Kenya) and Simon Busuttil MP (Malta) and myself as the first President. My background is as the Chairman of the United Kingdom All Party Parliamentary Group for Diabetes and Chariman of ExPAND. I have also lived with Type 1 diabetes for a quarter of a century. The PDGN will create a platform to raise the profile of diabetes within governments across the world. Through the communication of ideas and best practice and the encouragement of action within parliaments around the world, we can move towards the better allocation of resources and effort to prevent, diagnose and treat diabetes.

\section{The need for action}

The urgency required cannot be over-stated given the rising tide of diabetes across all continents and countries rich and poor. Already the scale of the challenge threatens the healthcare budgets of most countries and the economies of many.

There are over 382 million people with diabetes, most of whom are aged between 40 and 59, and $80 \%$ of them live in low- and middle-income countries. All types of diabetes are on the increase, type 2 diabetes in particular: the number of people with diabetes will increase by $55 \%$ by $2035 .{ }^{6}$ An additional 21 million cases of hyperglycaemia in pregnancy are estimated to contribute to the global burden of diabetes: that is equivalent to $17 \%$ of live births to women in 2013 that had some form of high blood glucose in pregnancy.

In human as well as financial terms, the burden of diabetes is enormous, provoking 5.1 million deaths and taking up some 
Box 1 The Melbourne Declaration on Diabetes.

We commit ourselves to working across Parliaments with all who have a special interest in diabetes and hereby agree to establish a 'Parliamentarians for Diabetes' global network with the following objectives to:

1. Exchange policy views and practical initiatives of relevance and to hear from experts on opportunities for action and progress in the prevention and management of diabetes. To always strive for 'best practice', and advocate for people with diabetes, their families and carers, and those at risk and to become a powerful force internationally to respond in a coordinated and focussed way to the diabetes pandemic and to promote the diabetes cause.

2. Provide parliamentarians with the opportunity to attend meetings organised by the IDF and their Member Associations, aiming to improve health outcomes for people with diabetes, stop discrimination towards people with diabetes and prevent development of type 2 diabetes. A special focus should be the different regions of the globe to ensure practical solutions are offered.

3. Establish a platform for the dialogue between IDF Member Associations and other stakeholders to exchange information and discuss special areas of common interest. These will include prevention, workforce, costs of diabetes, access to medicines, and effective strategies to combat and manage the pandemic. To report back to ministers, parliamentarians and other key decision-makers in our home countries and to seek commitments to deliver on the targets set at the 66th WHA in 2013. The global network will support the sharing of resources such as research, legislative initiatives, prevention campaigns and joint initiatives relevant to the various regions of the globe.

4. Encourage all governments to acknowledge that diabetes is a national health priority that requires a comprehensive action plan leading to action.

5. Respond to and participate in relevant debate and discussion on and related to the World Health Assembly, World Health Organisation, United Nations and other appropriate organisations or government bodies and specifically to ensure the inclusion of diabetes and NCDs in the post-2015 development framework noting this framework should be aligned with the goals and targets on diabetes agreed at the 66th WHA. Diabetes intersects all major dimensions of global development, including poverty reduction, gender inequality, education, environmental sustainability and infectious diseases.

6. Confer honour and express gratitude to those Members of Parliament supporting the diabetes cause, wherever they may be and to use our best endeavours to recruit other Members of Parliament for this purpose.

7. Create opportunities for networking and building relationships between Members of Parliament, other key decision-makers, the IDF and its Member Associations and others. To hold meetings in various regions of the globe as agreed, and to meet again as a Global Forum at the next World Diabetes Congress in 2015.

8. Appoint a global co-ordinator with appropriate administrative and management support to assist the global network to achieve the above objectives.

548 billion US dollars in health spending (11\% of the total spent worldwide) in 2013.

The priority of the PDGN in its early years will be to build a coalition of advocates for action to tackle the pandemic at local, regional, national and trans-national level. The focus will be on raising the matter in parliaments and assemblies across the globe

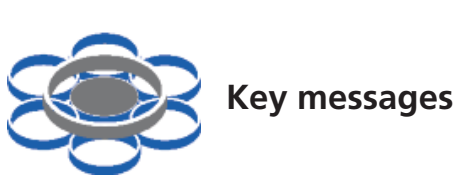

- First ever global network of Parliamentarians

- Aim to influence health policies across the globe

- Target to reach a tipping point where no one questions the prioritisation of diabetes

to spread better understanding and awareness of diabetes and the urgency with which it needs to be addressed.

From Bolivia to Scotland, several Parliaments and Assemblies have already endorsed or debated the Melbourne Declaration on Diabetes. Following the Melbourne Declaration a group of Parliamentarians has formed in the Russian Duma to advocate for diabetes, while in Europe a complementary initiative, the ExPAND Diabetes Toolkit, has just gone live that will greatly assist the aims of the declaration. ${ }^{7}$

\section{ExPAND}

The ExPAND Diabetes Policy Toolkit is a practical guide to help diabetes advocates challenge national governments to raise the profile of diabetes. It is the first comprehensive resource aimed specifically at helping MPs and other policy makers to shape and influence national policy to ensure we prepare our healthcare systems for the challenges of the 21st century. ${ }^{7}$

With input from parliamentarians, patient representatives and other opinion formers, the ExPAND toolkit provides a onestop resource covering the economic case for investment, evidence of what works, and best practice from across Europe as well as practical steps for leading and developing new diabetes policies fit for purpose. Key topics include prevention, self-management, innovation and person-centered care. There are also dedicated chapters to care and treatment of children and older people.

The EXPAND toolkit is a resource to turn words into action. ${ }^{7}$

\section{Conclusion}

It is a great honour to be tasked with leading this unique group and I am grateful for the support and guidance of the International Diabetes Foundation through its President Sir Michael Hirst, his co-chair behind the initiative, former Australian Senator, Guy Barnett, and the global co-ordinator the Network has appointed, the Hon Judi Moylan. A formidable back-up to what I hope will become a positive force governments will not be able to ignore.

While the Melbourne Declaration on Diabetes is a clarion call for action across the world, we also need momentum to reach that tipping point where no one questions why the global pandemic of diabetes receives priority attention for resources to prevent, diagnose and treat the condition.

\section{Conflict of interest None}




\section{Funding sources None}

\section{References}

1. EURADIA. http://www.euradia.org/ (Accessed March 2014)

2. Workshop Report. Diabetes care and research in Europe: the St Vincent Declaration. Diabet Med 1990;7:360.

http://dx.doi.org/10.1111/j.1464-5491.1990.tb01405.x

3. Felton A-M, Hall MS. Diabetes - from St Vincent to Glasgow. Have we progressed in 20 years? $\mathrm{Br} /$ Diabetes Vasc Dis 2009;9:142-4. http://dx.doi.org/10.1177/1474651409341318
4. Keen H. Translating wish lists to blueprints: A National Service Framework for diabetes. $\mathrm{Br}$ J Diabetes Vasc Dis 2001;1:57-61. http://dx.doi.org/10.1177/14746514010010010901

5. The Melbourne Declaration on Diabetes https://www.idf.org/sites/default/files/Melbourne_Declaration.pdf (Accessed March 2014)

6. IDF Diabetes Atlas, 6th edn. International Diabetes Federation 2013 www.idf.org/diabetesatlas

7. The ExPAND Toolkit www.idf.org/sites/default/files/ExPandPolicyToolkitonDiabetes_0.pdf (Accessed February 2014) 